\title{
Platelet-Rich Plasma in Cosmetic Surgery
}

\author{
Robert S Kang, Matthew K Lee, Rahul Seth, Gregory S Keller
}

\begin{abstract}
Platelet-rich plasma (PRP) is blood plasma containing an above baseline level of platelets and growth factors. PRP is an emerging new treatment utilized to enhance wound healing and has been in clinical use over the last several decades within many disciplines, such as orthopedic, oral-maxillofacial and cardiac surgery. Recently, PRP has come to the attention of esthetic surgeons, with burgeoning new applications ranging from hair restoration to soft tissue augmentation. The goal of this review is to describe the current body of literature on PRP as it pertains to the field of esthetics, and to review its current real-world applications. PRP's utility in cosmetic surgery is rapidly growing and offers a promising and exciting new therapeutic modality.
\end{abstract}

Keywords: Platelet-rich plasma, Cosmetics, Review.

How to cite this article: Kang RS, Lee MK, Seth R, Keller GS. Platelet-Rich Plasma in Cosmetic Surgery. Int J Otorhinolaryngol Clin 2013;5(1):24-28.

\section{Source of support: Nil}

Conflict of interest: None declared

\section{INTRODUCTION}

This article explores the clinical uses of platelet-rich plasma (PRP) in cosmetic surgery. PRP has been in clinical use over the last several decades and has been reported within many disciplines such as orthopedic, oral-maxillofacial and cardiac surgery. ${ }^{1-16}$ It has largely been investigated for its proposed ability to improve both hard and soft tissue wound healing. More recently, there has been a growing body of literature reporting its value in skin rejuvenation and augmentation of soft tissues in the realm of esthetics. It has been studied both in vitro and in animal models as well as in patients in various clinical settings.

PRP is defined simply as plasma containing abovebaseline concentrations of platelets. ${ }^{17} \mathrm{PRP}$ is isolated through the centrifugation of whole blood and the resultant density-based separation of its contents. Simply put, its actions are based on the infusion of elevated concentrations of the growth factors secreted by activated platelets, thereby theoretically enhancing the biological healing capacity and tissue generation in the wound bed. Enzyme-linked immunosorbent assay studies of PRP have quantified the presence of 7, 10 and 30-fold increases in such growth factors as transforming growth factor (TGF)- $\beta$, epidermal growth factor (EGF), platelet-derived growth factor (PDGF) respectively. ${ }^{18}$

The process of wound healing is orchestrated by the complex interaction of a variety of biochemical mediators.
Platelets play a prominent role in part through their secretion of numerous biologically active proteins. ${ }^{19,20}$ Damaged vascular endothelium exposes circulating platelets to activating agents, such as collagen and von Willebrand factor (vWF), causing them to morph from their circulating disk shapes into spiculated spheres with adherent pseudopodia. Aggregation of platelets at the site of injury leads to formation of a platelet plug, which further stimulates clot development via both intrinsic and extrinsic clotting pathways. ${ }^{21,22}$ Platelet activation results in release of intracellular $\alpha$-granules, releasing growth factors into the wound environment. Examples of these growth factors and cytokines include PDGF, TGF- $\beta$, vascular endothelial growth factor (VEGF), platelet activating factor (PAF), EGF, insulin-like growth factors (IGF)-1 and -2, vWF, fibrinogen and fibronectin. ${ }^{23-28}$ These bioactive proteins stimulate a host of activities, such as osteoblast, fibroblast and epidermal cell differentiation and proliferation, collagen synthesis and angiogenesis. ${ }^{29,30}$ Various cells involved in the different phases of wound healing are attracted to the site of injury, such as neutrophils, T-lymphocytes and monocytes. The latter cells differentiate into macrophages and eventually assume a chief regulatory role. ${ }^{30,31}$ This sequence of inflammatory cell chemotaxis and the differentiation and proliferation of progenitor cells ultimately leads to tissue regeneration. ${ }^{32,33}$

\section{CLINICAL APPLICATION OF PRP}

\section{Current Applications of PRP}

\section{Noncosmetic Applications of PRP}

PRP has been used to augment wound healing in various clinical situations. Bony and cartilaginous repair using PRP has been studied in such settings as periodontal disease, sinus augmentation, bisphosphonate-related osteonecrosis of the jaw, mandibular bone grafts and degenerative joint disease. ${ }^{34}$ Studies of soft tissue repair have examined disorders, such as rotator cuff injury, lateral epicondylitis, burns and chronic wounds. ${ }^{35-39}$ These studies describe varying effects from equivalence with placebo saline or anesthetic injections, to decreased postoperative pain and faster rates of healing.

\section{Hemostatic Properties of Autologous Blood Products}

In the realm of plastic surgery, the use of autologous blood products was first introduced over 20 years ago in the form 
of fibrin glue, which was used as a hemostatic agent to promote adherence of skin flaps. ${ }^{40}$ Early studies evaluating the use of fibrin glue in facelift patients demonstrated statistically significant decreases in both major hematoma formation and ecchymosis as well as elimination of the need for drains. ${ }^{41}$ However, more recent comparative studies have tempered these results, showing minimal differences in the incidence of these adverse events despite use of fibrin glue. $^{42,43}$ Fibrin glue is distinguished from PRP by its creation from platelet-poor plasma and primary composition of fibrinogen. By contrast, platelet gels contain higher concentrations of platelets and growth factors. Powell et al reviewed the effects of unilateral application of platelet gel in deep plane rhytidectomy in a small cohort of eight patients and found a nonsignificant trend for improved ecchymosis. ${ }^{44}$ These initial investigations into the wound healing properties of autologous blood products were the early foundation for further studies exploring the rejuvenative properties of PRP.

\section{PRP for the Treatment of Rhytids}

In addition to the hemostatic properties of platelet-rich substances, the role of PRP in facial skin rejuvenation and the treatment of rhytids are also under investigation. The efficacy of PRP in the treatment of skin wrinkles has been explored using an animal model by Cho et al. ${ }^{45}$ In this study, mice were first photoaged using UV-B irradiation for 8 weeks, and then divided into treatment groups either via PRP, normal saline or no treatment. Histologic assessment was subsequently performed using skin biopsy specimens, with the PRP-treated group demonstrating increased fibroblast and collagen production as well as increased dermal thickness. ${ }^{45}$ These effects has been corroborated by clinical studies in humans. Redaelli et al (2010) reported their results of 23 consecutive patients who received injections with PRP once a month for 3 months, demonstrating clinical improvement in skin tonicity as well as reduction of facial rhytids. ${ }^{46}$

\section{Augmentation of the Wound Healing Response}

Given that platelets play a key role in the body's natural wound healing response, the role of PRP application in conjunction with other skin rejuvenation procedures has been investigated to elucidate its efficacy in potentially reducing surgical recovery time. With fractionated laser resurfacing, the vaporized holes in the skin are produced which act as avenues for drug delivery, facilitating easy topical administration of the PRP. Na et al examined the benefits of PRP in the wound healing process following
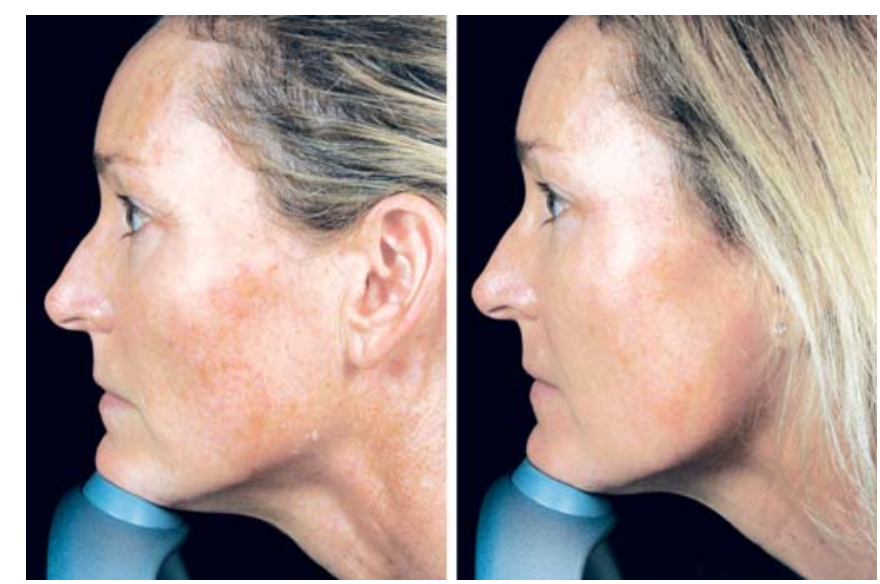

Fig. 1: Right: Preoperative profile photograph; Left: 5 days following $\mathrm{CO}_{2}$ laser resurfacing, demonstrating minimal erythema

fractional carbon dioxide laser resurfacing in 25 patients. They noted a significant decrease in recovery time in the treatment of inner arm soft tissue with PRP compared to controls treated with normal saline, demonstrated by less transepidermal water loss, erythema and inflammatory pigmentation. ${ }^{47}$ Similarly, Lee et al combined PRP with fractional carbon dioxide laser resurfacing for acne scars. The authors compared the experimental PRP-treated facial half to the normal saline-treated control half in 14 patients and noted a significant decrease in erythema, edema and overall improved appearance on the PRP-treated side. ${ }^{48}$ Recently, the senior author (GSK) has also explored the role of PRP in augmenting the skin healing response following $\mathrm{CO}_{2}$ laser resurfacing procedures. $\mathrm{CO}_{2}$ laser resurfacing of the face was performed with and without the topical application of PRP, with preliminary results demonstrating faster healing rates, decreased skin erythema (Fig. 1). ${ }^{49}$ Further investigation is currently ongoing.

\section{Applications of Platelet-rich Fibrin Matrix}

Platelet-rich fibrin matrix (PRFM) is a similar product to PRP that contains a smaller concentration of platelets. ${ }^{50}$ Like PRP, it has been similarly utilized to augment healing while attempting to more closely mimic the natural wound response. ${ }^{51}$ A calcium chloride solution is introduced to autologous blood, causing fibrin polymerization and development of a 3-dimensional matrix upon which platelets and growth factors are embedded. This scaffolding helps to localize growth factors to the targeted area. ${ }^{51}$ Sclafani described its use in the treatment of facial acne scarring, reporting enhancement in appearance using subcision to lyse the scar-tethering subdermal bands with a Nocor needle (Becton, Dickinson and Co., Franklin Lakes, NJ) followed by subdermal injection of up to 2 to 4 cc of PRFM per cheek. $^{50}$ 
Role of PRFM and PRP in Soft Tissue Augmentation

Another promising use for both PRFM and PRP is as a soft tissue augmenting agent. Various injectable materials, including matrices, such as collagen and hyaluronic acid, have been used for years for esthetic soft tissue augmentation. However, these agents have demonstrated variable degrees of resorption, requiring repeat injections in order to maintain volume. In theory, combining a soft tissue augmenting agent, such as hyaluronic acid with PRP may be synergistic in its effect, as the HA acts as a scaffold upon which the PRP induces collagen and adipocyte generation. When injected in combination with conventional soft tissue fillers, PRP has been shown in animal models to both augment and maintain the tissue volumizing effect. ${ }^{52}$ Runels has described the use of hyaluronic acid in combination with PRP in facial and breast injection augmentation. Promising esthetic results have been demonstrated using this technique, and outcomes studies are ongoing. ${ }^{49}$

Even when used as a standalone agent without conventional fillers, PRP has demonstrated the ability to augment soft tissue. Sclafani has demonstrated good results with dermal augmentation in the nasolabial folds using PRFM. ${ }^{53}$ In a series of 15 patients, the appearance of the nasolabial folds was improved in 1 to 2 weeks, with stable results at 12 weeks. Sclafani and McCormick performed histologic evaluations of full thickness skin biopsies taken from four subjects who had deep dermal and subdermal injections of PRFM. ${ }^{54}$ They observed activated fibroblasts and new collagen deposition by day 7, and development of new blood vessels and intradermal adipocytes as well as stimulation of subdermal adipocytes by day 19 . This study served to better elucidate the mechanism of volume enhancement observed after the injection of PRFM.

Additionally, autologous fat grafting has been supplemented with PRP with the intent of enhancing graft take, with current studies illustrating mixed results. Salgarello et al observed no effect in a retrospective review of 42 women who underwent breast fat grafting using outcome parameters of ultrasound-graded liponecrosis and need for further grafting. ${ }^{55}$ Cervelli et al reported the opposite findings, with improved subjective patient-reported outcomes as well as volume retention and revision grafting rates. ${ }^{56}$ Sclafani ${ }^{50}$ and Azzena ${ }^{57}$ observed decreased ecchymosis and maintenance of volume in autologous fat transfer with PRFM.

\section{Hair Restoration}

Recently, the role of PRP for the treatment of hair loss has also proven promising. Utilizing a mouse animal model, $\mathrm{Li}$ et al demonstrated that PRP stimulates hair regrowth by both prolonging the anagen phase of the hair cycle and by inducing antiapoptotic effects on dermal papilla cells. ${ }^{58}$ In human clinical studies, Takikawa et al studied the effects of PRP scalp injections in 26 subjects with thinning hair. ${ }^{59}$ A single $3 \mathrm{ml}$ injection of PRP with or without growth factorcarrier microparticles was injected into half of the scalp, and saline injected into the other half. Compared to the control half, the PRP-injected scalp demonstrated significantly thicker and increased numbers of hairs. Histologic analysis revealed thickened epithelium and proliferation of collagen, fibroblasts and vasculature. This supported earlier data reported by Uebel et al, who demonstrated an increased hair yield rate following follicular unit hair implantation with PRP. ${ }^{60}$

\section{CLINICAL PREPARATION OF PRP}

While many PRP preparation protocols exist, a common method involves drawing whole blood into a vial containing an anticoagulant. The blood is then centrifuged to separate the components based on variations in specific gravity: The bottom layer is comprised of red blood cells, the middle layer (often referred to as the buffy coat) white blood cells and platelets and the top layer plasma. The red blood cell portion is discarded, and the remaining plasma is centrifuged a second time to isolate the platelet-rich layer. Calcium chloride is then added to the resultant pellet of platelets and plasma, inducing platelet activation and release of alphagranule contents. ${ }^{61-63}$ Secretion of granule contents begins and fibrin polymerization occurs within 10 minutes of the onset of the clotting process, thereby necessitating the application of the prepared plasma within this timeframe. ${ }^{63}$

Another method of preparation involves drawing whole blood into a vial containing a separator gel. Upon centrifugation, the red and white blood cell layers are forced beneath the gel, on top of which settle the platelet layer and plasma. The platelets are then resuspended in the plasma by simply overturning the vial prior to use. The achievable concentration of platelets varies with the method of preparation employed, and has been reported from 2- to 8.5-fold over baseline (Table 1).

Of note, surgical wounds induce platelet activation and decrease whole blood platelet count due to platelet concentration at the site of surgery. As these effects may interfere with the preparation of PRP, it has been suggested

Table 1: Substance levels in physiologic vs PRP clots

\begin{tabular}{lll}
\hline & Physiologic clot & PRP clot \\
\hline Red blood cells & $35-50 \%$ hematocrit & $<1 \%$ hematocrit \\
Platelets & Native level & $2-4$ times native level \\
Growth factors & Native level & $2-4$ times native level \\
Fibrinogen & Native level & Native level \\
\hline
\end{tabular}


that blood be drawn prior to incision when surgery is concurrently performed. ${ }^{9,12,17}$ Prior to activation, PRP can be stably maintained in an anticoagulated state for up to 8 hours for use throughout a lengthy surgical procedure.

Currently, there are several commercially available systems which can be used for the preparation of autologous platelet-rich products. Selphyl (esthetic factors; Wayne, NJ, USA) and RegenKit (RegenLab; Lausanne, Switzerland) are two of the most commonly used systems, and are used to prepare PRFM and PRP respectively. Both of these systems have received FDA approval.

\section{CONCLUSION}

Many factors may influence the outcome of PRP usage, including platelet concentration and condition, amount of plasma used, the extent of injury at the site of treatment, and patient medical conditions. Such areas of potential clinical variability should be taken into account when examining the reported literature. The ease with which PRP can be prepared and applied heightens its appeal in cosmetic surgery. If studies continue to demonstrate desirable results, its adoption into practice could be easily facilitated.

\section{REFERENCES}

1. Anitua E, Sánchez M, Prado R, Orive G. Plasma rich in growth factors: The pioneering autologous technology for tissue regeneration. J Biomed Mater Res A 2011;97(4):536.

2. Bose B, Balzarini MA. Bone graft gel. Autologous growth factors used with autograft bone for lumbar spine fusions. Adv Ther 2002;19(4):170-75.

3. Della Valle A, Sammartino G, Marenzi G, Tia M, Espedito di Lauro A, Ferrari F, et al. Prevention of postoperative bleeding in anticoagulated patients undergoing oral surgery: Use of platelet-rich plasma gel. J Oral Maxillofac Surg 2003;61(11):1275-78.

4. DelRossi AJ, Cernaianu AC, Vertrees RA, Wacker CJ, Fuller $\mathrm{SJ}$, Cilley JH, et al. Platelet-rich plasma reduces postoperative blood loss after cardiopulmonary bypass. J Thorac Cardiovasc Surg 1990;100(2):281-86.

5. Froum SJ, Wallace S, Tarnow DP, Cho S. Effect of plateletrich plasma on bone growth and osseointegration in human maxillary sinus grafts: Three bilateral case reports. Int $\mathrm{J}$ Periodontics Restorative Dent 2002;22(1):45-53.

6. Hee HT, Majd ME, Holt RT, Myers L. Do autologous growth factors enhance transforaminal lumbar interbody fusion? Eur Spine J 2003;12(4):400-07.

7. Kassolis JD, Rosen PS, Reynolds MA. Alveolar ridge and sinus augmentation utilizing platelet-rich plasma in combination with freeze-dried bone allograft: Case series. J Periodontol 2000;71(10):1654-61.

8. Lowery GL, Kulkarni S, Pennisi AE. Use of autologous growth factors in lumbar spinal fusion. Bone 1999;25(2 Suppl):47S$50 \mathrm{~S}$.

9. Man D, Plosker H, Winland Brown JE. The use of autologous platelet-rich plasma (platelet gel) and autologous platelet-poor plasma (fibrin glue) in cosmetic surgery. Plast Reconstr Surg 2001;107(1):229-37.

10. Margolis DJ, Kantor J, Santanna J, Strom BL, Berlin JA. Effectiveness of platelet releasate for the treatment of diabetic neuropathic foot ulcers. Diabetes Care 2001;24(3):483-88.
11. Marx RE, Carlson ER, Eichstaedt RM, Schimmele SR, Strauss JE, Georgeff KR. Platelet-rich plasma: Growth factor enhancement for bone grafts. Oral Surg Oral Med Oral Pathol Oral Radiol Endodontol 1998;85(6):638-46.

12. Petrungaro PS. Using platelet-rich plasma to accelerate soft tissue maturation in esthetic periodontal surgery. Compend Contin Educ Dent 2001;22(9):729-32, 734, 736 passim.

13. Robiony M, Polini F, Costa F, Politi M. Osteogenesis distraction and platelet-rich plasma for bone restoration of the severely atrophic mandible: Preliminary results. J Oral Maxillofac Surg 2002;60(6):630-35.

14. Soffer E, Ouhayoun JP, Anagnostou F. Fibrin sealants and platelet preparations in bone and periodontal healing. Oral Surg Oral Med Oral Pathol Oral Radiol Endodontol 2003;95(5):521-28.

15. Welsh WJ. Autologous platelet gel: Clinical function and usage in plastic surgery. Cosmetic Derm 2000;11:13.

16. Whitman DH, Berry RL, Green DM. Platelet gel. An autologous alternative to fibrin glue with applications in oral and maxillofacial surgery. J Oral Maxillofac Surg 1997;55(11): 1294-99.

17. Marx RE. Platelet-rich plasma (PRP): What is PRP and what is not PRP? Implant Dent 2001;10(4):225-28.

18. Babbush CA, Kevy SV, Jacobson MS. An in vitro and in vivo evaluation of autologous platelet concentrate in oral reconstruction. Implant Dent 2003;12(1):24-34.

19. Anitua E, Andia I, Ardanza B, Nurden P, Nurden AT. Autologous platelets as a source of proteins for healing and tissue regeneration. Thromb Haemost 2004;91(1):4-15.

20. Marx RE. Platelet-rich plasma: Evidence to support its use. J Oral Maxillofac Surg 2004;62(4):489-96.

21. Conley CL. Hemostasis. In: Mountcastle VB (Ed). Medical Physiology. St. Louis: Mosby 2004:1137-46.

22. Caro CD, Pedley TJ, Schroter RC, et al. The mechanics of the circulation. Oxford: Oxford University Press 1978:149-74.

23. Sclafani AP. Applications of platelet-rich fibrin matrix in facial plastic surgery. Facial Plast Surg 2009;25(4):270-76.

24. Buckwalter JA, Einhorn TA, Bolander ME, et al. Healing of musculoskeletal tissues. In: Rockwood CA Jr, Bucholz RW, Green DP (Eds). Fractures in Adults. Philadelphia: LippincottRaven 1996:261-304.

25. Anderson JM. The cellular cascades of wound healing. In: Davies JE (Ed). Bone engineering. Toronto: Em Squared Inc 2000:81-93.

26. Bhanot S, Alex JC. Current applications of platelet gels in facial plastic surgery. Facial Plast Surg 2002;18(1):27-33.

27. Froum SJ, Wallace S, Tarnow DP, Cho S. Effect of plateletrich plasma on bone growth and osseointegration in human maxillary sinus grafts: three bilateral case reports. The Int $\mathrm{J}$ Periodon \& Restor Dent 2002;22(1):45-53.

28. Weibrich G, Kleis WK, Hafner G, Hitzler WE. Growth factor levels in platelet-rich plasma and correlations with donor age, sex, and platelet count. J Craniomaxillofac Surg 2002;30(2):97-102.

29. Rai B, Oest ME, Dupont KM, Ho KH, Teoh SH, Guldberg RE. Combination of platelet-rich plasma with polycaprolactonetricalcium phosphate scaffolds for segmental bone defect repair. J Biomed Mater Res A 2007;81(4):888-99.

30. Cho J, Kim S, Lee K. Platelet-rich plasma induces increased expression of G1 cell cycle regulators, type I collagen, and matrix metalloproteinase-1 in human skin fibroblasts. Int J Mol Med 2012;29(1):32-36.

31. Tischler M. Platelet rich plasma. The use of autologous growth factors to enhance bone and soft tissue grafts. NY State Dent J 2002;68(3):22-24.

32. Anitua E, Andia I, Ardanza B, Nurden P, Nurden AT. Autologous platelets as a source of proteins for healing and tissue regeneration. Thrombosis and Haemostasis 2004;91(1):4-15. 
33. Curi MM, Cossolin GS, Koga DH, Zardetto C, Christianini S, Feher $\mathrm{O}$, et al. Bisphosphonate-related osteonecrosis of the jaws - an initial case series report of treatment combining partial bone resection and autologous platelet-rich plasma. J Oral Maxillofac Surg 2011 Sep;69(9):2465-72.

34. Randelli P, Arrigoni P, Ragone V, Aliprandi A, Cabitza P. Platelet rich plasma in arthroscopic rotator cuff repair: A prospective RCT study, 2-year follow-up. J Shoulder Elbow Surg 2011 Jun;20(4):518-28.

35. de Vos RJ, Weir A, van Schie HT, Bierma-Zeinstra SM, Verhaar $\mathrm{JA}$, Weinans $\mathrm{H}$, et al. Platelet-rich plasma injection for chronic Achilles tendinopathy: A randomized controlled trial. JAMA 2010 Jan 13;303(2):144-49.

36. Mishra A, Pavelko T. Treatment of chronic elbow tendinosis with buffered platelet-rich plasma. Am J Sports Med 2006;34(11):1774-78.

37. Filardo G, Kon E, Della Villa S, Vincentelli F, Fornasari PM, Marcacci M. Use of platelet-rich plasma for the treatment of refractory jumper. Int Orthopaed 2010;34(6):909-15.

38. Gosens T, Peerbooms JC, van Laar W, den Oudsten BL. Ongoing positive effect of platelet-rich plasma versus corticosteroid injection in lateral epicondylitis: A double-blind randomized controlled trial with 2-year follow-up. Am J Sports Med 2011 Jun;39(6):1200-08.

39. Pallua N, Wolter T, Markowicz M. Platelet-rich plasma in burns. Burns 2010 Feb;36(1):4-8.

40. Ellis DA, Shaikh A. The ideal tissue adhesive in facial plastic and reconstructive surgery. J Otolaryngol 1990;19(1):68-72.

41. Marchac D, Sándor G. Face lifts and sprayed fibrin glue: An outcome analysis of 200 patients. Br J Plast Surg 1994; 47(5):306-09.

42. Marchac D, Greensmith AL. Early postoperative efficacy of fibrin glue in face lifts: A prospective randomized trial. Plast Reconstr Surg 2005;115(3):911-16.

43. Jones BM, Grover R. Avoiding hematoma in cervicofacial rhytidectomy: A personal 8-year quest. Reviewing 910 patients. Plast Reconstr Surg 2004;113(1):381-87.

44. Powell DM, Chang E, Farrior EH. Recovery from deep-plane rhytidectomy following unilateral wound treatment with autologous platelet gel: A pilot study. Arch Facial Plast Surg 2001;3(4):245-50.

45. Cho JM, Lee YH, Baek R, Lee SW. Effect of platelet-rich plasma on ultraviolet b-induced skin wrinkles in nude mice. J Plast Reconstr Aesthet Surg 2011;64(2):e31-e39.

46. Redaelli A, Romano D, Marcianó A. Face and neck revitalization with platelet-rich plasma (PRP): Clinical outcome in a series of 23 consecutively treated patients. J Drugs Dermatol 2010;9(5):466-72.

47. Na JI, Choi JW, Choi HR, Jeong JB, Park KC, Youn SW, et al. Rapid healing and reduced erythema after ablative fractional carbon dioxide laser resurfacing combined with the application of autologous platelet-rich plasma. Dermatol Surg 2011;37: 463-68.

48. Lee JW, Kim BJ, Kim MN, Mun SK. The efficacy of autologous platelet rich plasma combined with ablative carbon dioxide fractional resurfacing for acne scars: A simultaneous split-face trial. Dermatol Surg 2011;37:931-38.

49. Keller GS, Kang RS. Biostimulation of our own cells for skin rejuvenation. Oral presentation. AAFPRS Rejuvenation of the Aging Face, San Diego, CA, January 2012.

50. Sclafani AP. Applications of platelet-rich fibrin matrix in facial plastic surgery. Arch Facial Plast Surg 2009 Nov;25(4):270-76.

51. Sclafani AP. Safety, efficacy, and utility of platelet-rich fibrin matrix in facial plastic surgery. Archives of Facial Plastic Surgery 2011;13(4):247-51.
52. Okabe K, Yamada Y, Ito K, Kohgo T, Yoshimi R, Ueda M. Injectable soft-tissue augmentation by tissue engineering and regenerative medicine with human mesenchymal stromal cells, platelet-rich plasma and hyaluronic acid scaffolds. Cytotherapy 2009;11(3):307-16.

53. Sclafani AP. Platelet-rich fibrin matrix for improvement of deep nasolabial folds. J Cosmet Dermatol 2010;9:66-71.

54. Sclafani AP, McCormick SA. Induction of dermal collagenesis, angiogenesis, and adipogenesis in human skin by injection of platelet-rich fibrin matrix. Arch Facial Plast Surg 2011 Oct 17. Epub ahead of print.

55. Salgarello M, Visconti G, Rusciani A. Breast fat grafting with platelet-rich plasma: A comparative clinical study and current state of the art. Plast Reconstr Surg 2011 Jun;127(6):2176-85.

56. Cervelli V, Gentile P, Scioli MG, Grimaldi M, Casciani CU, Spagnoli LG, et al. Application of platelet-rich plasma in plastic surgery: Clinical and in vitro evaluation. Tissue Eng Part C Methods 2009 Dec;15(4):625-34.

57. Azzena B, Mazzoleni F, Abatangelo G, Zavan B, Vindigni V. Autologous platelet-rich plasma as an adipocyte in vivo delivery system: Case report. Aesthetic Plast Surg 2008;32: 155-158; discussion 159-61.

58. Li Z J, Choi H, Choi D, Sohn K, Im M, Seo Y, et al. Autologous platelet-rich plasma: A potential therapeutic tool for promoting hair growth. Dermatol Surg 2012;38(7):1040-46.

59. Takikawa M, Nakamura S, Nakamura S, Ishirara M, Kishimoto S, Sasaki K, et al. Enhanced effect of platelet-rich plasma containing a new carrier on hair growth. Dermatol Surg 2011;37:1721-29.

60. Uebel CO, da Silva JB, Cantarelli D, Martins P. The role of platelet plasma growth factors in male pattern baldness surgery. Plast Reconstr Surg 2006;118:1458-66.

61. Bhanot S, Alex JC. Current applications of platelet gels in facial plastic surgery. Facial Plast Surg 2002;18:27.

62. Eppley BL, Woodell JE, Higgins J. Platelet quantification and growth factor analysis from platelet-rich plasma: Implications for wound healing. Plast Reconstr Surg 2004;114:1502.

63. Kevy S, Jacobson M. Preparation of growth factors enriched autologous platelet gel. Proceedings of the 27th Annual Meeting of Service Biomaterials, 2001 April.

\section{ABOUT THE AUTHORS}

\section{Robert S Kang}

Department of Head and Neck Surgery, Division of Otolaryngology City of Hope National Medical Center, Duarte, California, USA

\section{Matthew K Lee}

Department of Head and Neck Surgery, David Geffen School of Medicine, University of California, Los Angeles, California, USA

\section{Rahul Seth}

Department of Head and Neck Surgery, David Geffen School of Medicine, University of California, Los Angeles, California, USA

\section{Gregory S Keller}

Department of Head and Neck Surgery, David Geffen School of Medicine, University of California, Keller Facial Plastic Surgery Los Angeles, California, USA

Correspondence Address: 221 W Pueblo St., Santa Barbara, CA 93105, 805-687-6408, USA, e-mail: drgregorykeller@gmail.com 